\title{
DIÁLOGOS SOBRE PRÁXIS REFLEXIVA DOCENTE E A ADOÇÃO DO ENSINO REMOTO NO PROEJA
}

\author{
Aldo Rezende ${ }^{1}$ \\ Edna Castro de Oliveira ${ }^{2}$ \\ Maria José de Resende Ferreira ${ }^{3}$
}

\section{RESUMO}

O artigo problematiza a adoção do ensino remoto nos cursos técnicos integrados do Proeja no Ifes em tempos pandêmico e suas consequências, como possibilidade de mais uma interrupção da trajetória escolar dos estudantes da EJA. No contexto de naturalização de práticas educativas instrumentais e pragmáticas, alicerçadas nas diretrizes da educação a distância e que desconsideram as especificidades e as condições objetivas de sobrevivência desses educandos, recorremos aos pressupostos da epistemologia da práxis, estabelecendo nexos possíveis entre os estudos sócio-histórico-culturais de Vygotsky e o pensamento de Paulo Freire, na defesa da educação como prática da liberdade. As inferências da pesquisa documental e da sistematização da experiência permearam as análises em curso e permitiram apresentar um panorama, ainda que parcial, dos resultados da implementação do ensino remoto no Proeja como ameaça à formação humana

1 Doutor em Planejamento Urbano e Regional. Coordenador do Curso técnico Integrado de Hospedagem do Proeja do Ifes campus Vitória. Professor do Programa de Pós Graduação em Educação Profissional e Tecnológica (ProfEPT). Pesquisador na área de turismo, sub-área de geografia urbana, regional e cultural. ORCID: https://orcid.org/0000-0001-7239-1002. E-mail: aldorezendebh@gmail.com

2 Doutora em Educação. Professora associada da Universidade Federal do Espírito Santo - UFES. Integra a linha de pesquisa Educação, Formação Humana e Políticas Públicas do PPGE/CE/UFES. Compõe a coordenação do Núcleo de Educação de Jovens e Adultos do Centro de Educação da UFES. ORCID: https://orcid.org/0000-0003-0798-7090 . E-mail: oliveiraedna@yahoo.com.br

3 Doutora em Educação. Professora do Programa de Pós Graduação em Educação Profissional e Tecnológica (ProfEPT) do Ifes campus Vitória. Pesquisadora do campo de estudos da EJA e Trabalho e Educação, relações de gênero e educação étnico-raciais, diversidade e formação de professores. ORCID:. https://orcid.org/0000-0001-9442-0468. E-mail: majoresende@yahoo.com.br. 
integral, ressaltando a importância do papel ético-político dos educadores, na condição de mediadores dos processos de produção do conhecimento.

Palavras-chave: Práxis. Formação humana. Ensino remoto.

\section{DIALOGUES ON REFLECTIVE TEACHING PRAXIS AND THE ADOPTION OF REMOTE TEACHING AT PROEJA}

\section{ABSTRACT}

The article problematizes the adoption of remote teaching by the technical courses of Proeja at Ifes during the coronavirus pandemic and its consequences, as another possible interruption in the school trajectory of EJA's students. In time of naturalization of instrumental and pragmatic educational practices, guided by distance education principles that disregard the specificities and objective conditions of survival of EJAs students, we resorted to the assumptions of the epistemology of reflective praxis, establishing possible links between socio-historical studies and cultural aspects of Vygotsky and the thoughts of Paulo Freire, in the defense of education as a practice of freedom. The inferences from the documental research and the systematization of the experience permeated the ongoing analyzes and allowed to present an overview, albeit partial, of the results of the implementation of remote education at Proeja as a threat to integral human education, highlighting the importance of the ethical-political role of educators, as mediators of knowledge production processes.

Keywords: Praxis. Human formation. Remote teaching.

\section{DIÁlOGOS SOBRE LA PRAXIS PEDAGÓGICA REFLEXIVA Y LA ADOPCIÓN DE LA ENSENANZA A DISTANCIA EN PROEJA}

\section{RESUMEN}

El artículo problematiza la adopción del aprendizaje a distancia en los cursos técnicos integrados de Proeja en Ifes en tiempos de pandemia y sus consecuencias, como una posibilidad de otra interrupción en la 
trayectoria educativa de los estudiantes de EJA. En el contexto de naturalización de prácticas educativas instrumentales y pragmáticas, basadas en pautas de educación a distancia y que desconocen las especificidades y condiciones objetivas de supervivencia de estos estudiantes, se recurrió a los presupuestos de la epistemología de la praxis, estableciendo posibles vínculos entre los estudios sociohistóricos-culturales de Vygotsky y el pensamiento de Paulo Freire, en defensa de la educación como práctica de la libertad. Las inferencias de la investigación documental y la sistematización de la experiencia permearon los análisis en curso y permitieron presentar un panorama, aunque parcial, de los resultados de la implementación de la educación a distancia en Proeja como amenaza a la educación humana integral, destacando la importancia del rol ético-político de los educadores, como mediadores de los procesos de producción de conocimiento.

Palabras clave: Práxis. Formación humana. Enseñanza remota.

\section{INTRODUÇÃO}

Em tempos sombrios, assistimos cada vez mais ao recuo das teorias educacionais emancipatórias e ao avanço das concepções pragmáticas e instrumentais que, assumidas durante o processo de formação docente, acabam conformando práticas educativas voltadas para o imediatismo de intervenções paliativas e, por vezes, improvisadas. Emergem assim, intencionais e convenientes formas de enfrentar as questões do cotidiano da vida escolar; nesse particular, em um contexto histórico marcado por insistentes medidas governamentais de precarização da escola pública (FREITAS, 2018), quando prevalece a "pedagogia da flexibilidade" 4 (CAMARGO, ROSA, 2018; KUENZER, 2017).

4 Para Kuenzer (2017), as discussões acerca da flexibilização dos projetos e das práticas pedagógicas, no ensino médio, mediados pelas novas tecnologias de informação e comunicação são retomadas recentemente. "A aprendizagem flexível surge como uma das expressões do projeto pedagógico da acumulação flexível, cuja lógica continua sendo a distribuição desigual do conhecimento, porém com uma forma diferenciada. Assim, o discurso da acumulação flexível sobre a educação aponta para a necessidade da formação de profissionais flexíveis, que acompanhem as mudanças tecnológicas 
Mesmo que de forma sutil, trata-se de um intencional e histórico movimento de precarização, material e intelectual, da escola pública imbricado à reconhecida desqualificação do processo de produção do conhecimento elaborado, que tem como alvo o esvaziamento do papel dos profissionais da educação e, por conseguinte, o apagamento das matrizes teóricas e conceituais indutoras da práxis docente comprometida com os pressupostos teóricos e conceituais da proposta de formação humana integral (BRASIL, 2007).

$\mathrm{Na}$ perspectiva de potencializar uma maior compreensão e apreensão no campo da epistemologia da práxis, cabe-nos destacar que as práticas docentes precisam ser taticamente avaliadas e redimensionadas, notadamente, quando tensionadas, a exemplo do momento atual pautado pelas estratégias de fragmentação, ainda maior, do processo formativo escolar por meio das diretrizes contidas na reforma do ensino médio em curso: a base nacional comum curricular (BNCC). A reforma consiste em um projeto impulsionado a partir do golpe de 2016, seguido das eleições de 2018, com a ascensão do projeto neofascista de governo e do agravamento da crise sócio-econômica, marcada pela retração dos setores produtivos e pelo desemprego em ascensão.

É nesse cenário desolador, agravado pela crise sanitária ocasionada pela pandemia do Coronavírus SarsCoV-2 (Covid-19) que o projeto de reformas educacionais coaduna com o perverso jogo de redução da capacidade de investimentos do Estado brasileiro, com o desmonte das políticas sociais e de financeirização da economia com graves consequências sociais e econômicas que afetam diretamente as camadas populares, cada vez mais empobrecidas. Desde então, de forma paradoxal, no contraponto ao necessário enfrentamento da pandemia do novo Coronavírus, ganhou força a negação da ciência e das medidas de controle de contaminação, assim como a

decorrentes da dinamicidade da produção científico-tecnológica contemporânea, em vez de profissionais rígidos, que repetem procedimentos memorizados ou recriados por meio da experiência. Para que essa formação flexível seja possível, propõe-se a substituição da formação especializada, adquirida em cursos de educação profissional e tecnológica, por uma formação mais geral" (KUENZER, 2017, p. 338-339). 
prevaricação da campanha de vacinação. Na atualidade, o país já ultrapassa a marca histórica de mais de 600 mil vidas interrompidas.

A escola parou! As salas de aulas foram fechadas, as atividades letivas presenciais suspensas e, com as relações pessoais entre educadores e educandos interrompidas, ações paliativas passaram a ser adotadas, tendo em vista a manutenção do funcionamento do sistema de ensino privado, financeiramente abalado.

De forma paulatina, assistimos ao avanço da política de precarização da escola pública brasileira, por meio das iniciativas voltadas para a adoção de plataformas virtuais e de videoaulas, quase sempre veiculando conteúdos encomendados por empresas privadas. Tais aparatos tecnológicos passaram a fazer dos docentes meros repassadores de atividades nos moldes da produção "home office". Esses profissionais transformaram suas residências em salas de aula e se viram, cada vez mais, envolvidos nas exaustivas tarefas de produzir vídeos, realizar encontros virtuais, criar e monitorar grupos de estudantes, via whatsapps e e-mails, além de efetuar ligações telefônicas com a finalidade de motivar, orientar e atender educandos.

É nessa perspectiva de reflexão crítica que objetivamos contribuir com as discussões acerca do necessário e permanente repensar do papel dos educadores, na condição de intelectuais orgânicos, para o enfrentamento do projeto neoliberal, indutor da precarização material e intelectual da educação pública e de afirmação do tecnicismo-pragmático, consubstanciado no projeto de educação unilateral (GRAMSCI, 2000).

No campo da epistemologia da práxis, destacamos as importantes contribuições dos pensamentos de Vygotsky e de Paulo Freire, no sentido de contribuir com o movimento de avaliação e de redimensionamento das práticas docentes, pela reafirmação dos educadores no papel de mediadores dos processos de produção do conhecimento, em especial, dos estudantes da modalidade de Educação de Jovens e Adultos (EJA), integrados ao Programa Nacional de Integração da Educação Básica com a Educação Profissional na Modalidade de Educação de Jovens e Adultos (Proeja) do Instituto Federal dos Espírito Santo (Ifes). 
Outrossim, considerados os argumentos iniciais apresentados, na sequência das pontuais relações entre as contribuições de Vygotsky e de Paulo Freire, objetivamos, por meio das orientações da pesquisa documental e da metodologia de sistematização de Experiência, evidenciar os paradoxos decorrentes das ações paliativas relacionadas às experiências de ensino remoto, adotadas nos Cursos Técnicos Integrados do Proeja do Ifes, Unidade Vitória, no contexto da crise sanitária do novo Coronavírus. Sem a pretensão de esgotar o movimento reflexivo, entendemos ser importante contribuir com o debate sobre o intencional movimento de precarização material e intelectual da educação pública brasileira, em especial para a modalidade de EJA.

\section{EPISTEMOLOGIA DA PRÁXIS: conhecimento e prática refletida}

A epistemologia é um ramo da Filosofia voltado para o estudo da origem e das possibilidades do conhecimento humano em sua complexidade. Uma permanente procura por respostas para questões inquietantes, notadamente em determinados momentos históricos, em especial no tempo presente, quando inúmeras e complexas questões nos movem para o permanente exercício de contextualizações, inclusive sobre e a partir do repensar a função social da escola pública, do projeto político da educação escolar e, por conseguinte, da intencionalidade política da ação educativa no campo da produção do conhecimento elaborado (CHAUí, 2010).

Nos termos do enunciado, a práxis revela-se, no âmago da relação entre teoria e prática, reflexo da estrutura do pensamento em movimento, mediante as possibilidades objetivas de compreender para uma maior apreensão, capaz de promover a emancipação, por meio da intervenção orientada, no sentido de potencializar os processos de transformação social (VAZQUEZ, 1968). É justamente nessa perspectiva da práxis reflexiva, problematizadora do realconcreto em suas contradições, que acreditamos ser possível redimensionar e dar concretude a novos sentidos e significados às práticas docentes, particularmente em contextos marcados por intencionais ameaças à educação pública, como sinalizado. 
Com esse entendimento crítico e emancipatório, a epistemologia da práxis na formação e na reflexão sobre a atuação de educadores, em especial na EJA, reitera a modalidade como importante área do conhecimento; portanto, indissociável das teorias do conhecimento crítico que fundamentam os debates relacionados ao campo da educação e da escola pública brasileira. É nesse horizonte que se tornam consideráveis as contribuições dos pensamentos vygotskyano e freireano. Ao revisitar as obras de Vygotsky e Freire, reiteramos a importância da epistemologia da práxis no sentido de exercitar, de forma fundamentada, a problematização do movimento de aparente naturalização das práticas docentes, no atual contexto da pandemia e pandemônios ${ }^{5}$.

Mediante as permanentes ameaças à escola pública, torna-se inconcebível deixar prevalecer a condição de heteronomia ${ }^{6}$, em especial de educadores, em muitos casos, cerceados tanto pelo movimento escola sem partido como pela campanha de negação à importância do conhecimento científico; e no contexto da pandemia do Coronavírus, pelo "canto da sereia" referente ao formato de ensino remoto. Tal formato se mostra improvisado e enviesado pelos clichês frequentemente propalados: "novo normal", "homeoffice", "educação remota emergencial", "ensino híbrido alternativo" e "ensino remoto flexível", dentre outros termos de apelo ao encantamento imediato e, por conseguinte, de expressão da sutil tentativa de naturalização do

5 As pandemias referem-se às crises sanitária e a humanitária, trazidas pelo Covid-19 e aprofundadas pela situação de desigualdade social do país. O pandemônio diz respeito ao governo caótico do Presidente Jair Bolsonaro e a sua administração do momento pandêmico que vivenciamos (ARAGÃO, 2020).

6 "O conceito iluminista de autonomia, que adquire centralidade em Kant, foi essencial para o desenvolvimento da sociedade e da educação desde a modernidade. Kant propôs uma educação a partir da metafísica da subjetividade como uma ética aplicada; formulou tal sentido por meio de uma fundamentação filosófica racionalizada de autodeterminação e de autonomia. Para ele, o homem guiado pela sua razão universal agindo por dever, segundo o imperativo categórico, é autorresponsável e autônomo, enquanto o homem sensível que recebe influências externas à razão é o homem em condição de heteronomia. Em Paulo Freire, a autonomia ganha um sentido sóciopolítico-pedagógico, visto que cabe à educação formar o homem consciente e crítico, capaz de transformar as estruturas opressoras e alienantes, capaz de transformar as condições concretas de heteronomia. Para Freire, autonomia se dá a partir da práxis que leva à libertação" (ZATTI, 2007, p. 6). 
projeto neoliberal de reestruturação e desqualificação da educação pública.

Assim, no contraponto à condição de heteronomia resultantes das estratégias de opressão e alienação, para afirmar o indispensável sentido sócio-político da autonomia dos professores, o permanente esforço de revisão e de redimensionamento das práticas docentes apresenta-se como importante estratégia de promover a unidade das dimensões teóricas: teórico-epistemológica, técnico-científica, política e estética e prática, de forma fundamentada e comprometida com o estudo e com a reflexão crítica da práxis.

Mediante a complexidade do momento atual, marcado por experimentos improvisados e tentativas de naturalização do formato de ensino remoto nas escolas públicas, não menos redundante se torna considerar que, no campo da epistemologia da práxis, a própria etimologia da palavra remete-nos à expressão do sentido exato do "estudo do conhecimento" como estratégia de análise de determinadas teorias, indutoras da busca por respostas à determinadas questões. Assim, face às profundas reestruturações da educação escolar e novos "modus operandi" de produzir conhecimentos, é preciso problematizar: qual conhecimento? Para quem? A quem interessa?

Dessa forma, no âmbito da epistemologia da práxis, este estudo provocativo pauta pela necessidade de transpor a "zona do conforto" e ou "imobilismo" em que muitos educadores se encontram, plasmados, principalmente, pelo fetiche das tecnologias da informação enquanto alternativa única para fazer funcionar o sistema de ensino e para produzir conhecimentos nas escolas. O que se pretende é promover a reflexão crítica e, dessa forma, empoderar educadores e educadoras para, cada vez mais, questionar o projeto de educação "desinteressada" e as armadilhas de atendimento aos ditames e interesses do mercado, em especial na modalidade da EJA, em que, em muitos casos, predomina a concepção de educação tecnicista-pragmática (GRAMSCl, 2000).

No campo dos pressupostos filosóficos, metodológicos e pedagógicos a concepção materialista-histórica em muito contribui para a constituição do pensamento reflexivo, tendo em vista a complexidade do repensar criticamente e redimensionar as práticas 
docentes no contexto político atual, marcado por intencionais jogos de interesses das classes dominantes. Dessa forma, eivada pela fundamentação teórica, revela-se a práxis como ação humana transformadora a partir dos processos de produção do conhecimento que por meio da compreensão da realidade, permite a apreensão e as objetivas condições de intervir para transformar a realidade. Como assegurado por Vazquez (1968, p.152) "O objeto do conhecimento é produto da atividade humana, e como tal, não como mero objeto de contemplação, é conhecido pelo homem. O conhecimento é o conhecimento de um mundo criado pelo homem, isto é, inexistente fora da história, da sociedade e da indústria".

No âmbito da educação escolar, indissociável dos processos de produção de conhecimentos, a práxis, enquanto ação refletida, pavimenta o caminho da tomada de consciência e da emancipação dos sujeitos envolvidos na produção do conhecimento. Ainda de acordo com Vazquez (1968, p.108), a indissociabilidade entre teoria e práxis afirma-se enquanto,

[...] atividade humana que transforma o mundo natural e social para fazer dele um mundo humano, sem que por outro lado essa atividade seja concebida com um caráter estritamente utilitário. A práxis contém as dimensões do conhecer (atividade teórica) e do transformar (atividade prática), ou seja, teoria e prática são indissociáveis: "[...] fora dela fica a atividade teórica que não se materializa [...], por outro lado não há práxis como atividade puramente material, sem a produção de finalidades e conhecimentos que caracteriza a atividade teórica.

Nestes termos, o exercício de repensar o formato do ensino remoto na EJA reitera as questões até então apresentadas. Tomamos, como ponto de partida, os pressupostos da epistemologia da práxis no sentido de contribuir com as tentativas de compreender e apreender os processos educacionais a partir do real-concreto, em suas contradições e complexidades e, assim, redimensionar, na essência, o verdadeiro sentido da educação como práxis - ação humana transformadora, fundada no campo do conhecimento teórico-conceitual para, então, romper com a "naturalização" e o 
"imobilismo", visando a potencializar a educação no movimento da prática da liberdade e da emancipação. Isso se faz urgente na atual conjuntura, que exige a desnaturalização do "novo normal" e que insiste no pensamento único, bem como na condição heteronômica de expressiva parcela da sociedade.

\section{EDUCADOR MEDIADOR: revisitando aspectos pontuais dos estudos de Vygotsky.}

No campo da epistemologia da práxis, o repensamento e o redimensionamento das práticas pedagógicas não se esgotam apenas por meio da imersão na prática. A mediação teórica é elementar no processo de busca pela compreensão e apreensão da realidade em suas contradições e complexidades. Ou seja, a ação refletida somente terá sentido se embasada por um sólido campo teórico-conceitual capaz de suscitar novos e permanentes movimentos de "organização do espírito", em sua possibilidade de inovar para intervir e transformar.

No atual momento brasileiro, a crise sanitária corrobora o comportamento cada vez mais individualizado e impõe "ausências", rompimento de relações interpessoais, notadamente nos espaços habituais de convivência pública, a exemplo dos espaços escolares. Oportunidade em que são flagrantes os experimentos em tentativas de fazerem cumprir, de formas improvisadas, a dinâmica e a organização da escola.

Não obstante, o sentido da expressão "na ausência do outro, o homem não se constrói homem" (VYGOTSKY, 2002, p. 235) merece uma profunda reflexão capaz de dar conta do compromisso político e pedagógico - a práxis política de educadores, mediante a proposta de formação humana desejada dos sujeitos.

O permanente exercício de busca pela compreensão sobre os significados da educação como prática da liberdade (FREIRE, 1967) exige, cada vez mais, a responsabilidade histórica e social dos docentes no cotidiano de suas práticas educativas refletidas, com vista a criar condições objetivas e contribuir de forma efetiva com os 
processos de transformação da sociedade, em suas contradições cada vez mais agudizadas.

No exercício de busca pela compreensão sobre o sentido ético e político do "ser" e do "estar" no mundo, docentes e discentes, em grande parte, encontram-se expostos e bombardeados por ideologias e por mecanismos diversos de controle social, promovidos pelas elites dominantes por meio da grande mídia, em especial nas redes sociais. Uma histórica dominação de classe que se afirma de forma veemente e intensificada por meio das mídias, das seitas neopentecostais, entre outros mecanismos de dominação e alienação. Essas constatações têm colocado em cheque os valores democráticos e, de forma concomitante, também promovem a naturalização da barbárie no âmbito das relações interpessoais, cada vez mais latente na nossa sociedade.

Nessa conjuntura política marcada por profundas contradições e pela ascensão do projeto neofascista de poder, tornase imprescindível a nós, educadores, problematizar de forma fundamentada as práticas educacionais, a partir de teorias e conceitos sólidos no campo da Educação. Ao revisitar a obra de Vygotsky ${ }^{7}$, em suas importantes contribuições, somos levados a rever de forma permanente nossa postura e condição de educadores mediadores do processo de produção do conhecimento.

Portanto, não há redundância em reiterar alguns aspectos relacionados aos sentidos e significados da teoria sócio-históricocultural de Vygotsky, tendo em vista, notadamente, as considerações sobre a origem dos processos de mudanças possíveis, por meio das possibilidades de interações entre o indivíduo e a sociedade, em sua

7 "[...] A sistematização dos estudos de Vygotsky, realizada principalmente por seus colaboradores e seguidores, não foi tarefa fácil: seus textos eram complexos, traziam novas reflexões e dados de pesquisas inéditas, alguns não passavam de puros esquemas, fragmentos de proposições ou resumos de idéias, não raro registradas por outras pessoas, devido à saúde precária de seu autor. Dessa forma, não se pode afirmar que Vygotsky deixou uma teoria completa e estruturada. Não obstante, setenta anos após a sua morte, sua obra continua presente e atual, contribuindo para a prática de professores, pedagogos, psicólogos, psicopedagogos, dentre outros profissionais. Por fim, para que a contribuição de Vygotsky seja efetiva, faz-se necessário que seu legado seja revisitado com base em indagações suscitadas pela realidade histórica e cultural" (MIRANDA, 2004, p. 11). 
totalidade. Interações no âmbito das práticas docentes, em suas totalizações operadas também pelo uso da linguagem, enquanto instrumento de humanização por meio das inter-relações, bem como das vivências e experiências indispensáveis ao almejado alcance e ressignificações da gramática da relação sujeito-objeto do conhecimento.

No curso das reconhecidas complexidades, o desenvolvimento do indivíduo se efetiva como resultado de um processo sócio-histórico-cultural pautado, particularmente, por meio da linguagem e pela permanente interação dos sujeitos. Para Vygotsky (1993), a linguagem é o principal instrumento de intermediação do processo de construção do conhecimento, tratando-se, portanto, de um sistema simbólico, elementar para a concretude da relação sujeito-objeto.

No âmbito de seus estudos, são apresentados os conceitos: mediação simbólica, signos, sistemas de símbolos, zona de desenvolvimento proximal, desenvolvimento e aprendizado. São conceitos que sedimentam o campo teórico de compreensão e apreensão de destacados processos relacionados à construção do conhecimento, por meio das práticas educativas pautadas no permanente movimento de interação entre os sujeitos envolvidos.

Antes mesmo da busca pela relação entre teoria e prática, refletida no viés da concretude das práticas pedagógicas docentes, em especial de educadores comprometidos com os princípios básicos norteadores do Proeja (BRASIL, 2007), como política pública, revisitaremos, de forma pontual e articulada, os estudos vygotskiano e freireano, em seus conceitos estruturantes e indispensáveis, capazes de contribuírem com o exercício de repensar e redimensionar a prática educativa.

Nesse entendimento, torna-se possível desvelar algumas aproximações das ideias desses educadores. São diálogos que revelam, na totalidade do método de concepção e análise dos processos sócio-histórico e cultural, as peculiaridades inerentes à compreensão do real-concreto, das condições objetivas dadas para a produção do conhecimento e possibilidades de intervenção. Mesmo não se aproximando integralmente, no que tange aos pressupostos de origem do conhecimento e do decorrente processo de 
aprendizagem, são ideias que se complementam e que permitem aos educadores tomarem consciência das estratégias de opressão, alienação e dominação de classe.

Nesses termos, a consideração e valorização dos saberes, do conhecimento cotidiano, o papel dos sujeitos e os pressupostos relacionados ao processo de conscientização são alguns dos aspectos que permitem reconhecer diálogos possíveis entre os respectivos campos teóricos em pauta. A mediação simbólica por meio de instrumentos, signos e sistemas de signos traz o docente para o centro do processo ensino-aprendizagem, não como o detentor exclusivo do conhecimento a ser depositado. Trata-se de reconhecer o papel do educador como mediador do processo de produção do conhecimento nas mais diversas possibilidades e estratégias de estruturação e de articulação do saber compartilhado, a partir do meio social em que o próprio educador e os estudantes estão inseridos.

Ao considerar o desenvolvimento humano e a aprendizagem os temas centrais da teoria sócio-histórico-cultural de Vygotsky, o meio social, contextualizado face às estratégias articuladas de promoção do desenvolvimento cognitivo, mesmo que superficialmente, desvelam a importância do educador enquanto sujeito histórico, na condição de mediador no processo compartilhado de construção do conhecimento. Assim, sob a influência do meio social e cultural, a formação do sujeito autônomo reverbera a importância dos princípios básicos da teoria sóciohistórico-cultural de Vygotsky, em sua relação com os fundamentos teóricos do pensamento freireano, cimentados na mesma base epistemológica, qual seja, no materialismo histórico e dialético.

\section{EDUCAÇÃO LIBERTADORA: considerações à luz do pensamento freireano.}

No sentido de superação da educação bancária e conteudista, reconhecer e desvelar a realidade criticamente (FREIRE, 2006) são partes do processo de construção do conhecimento que, intermediado pelo docente, sinaliza para a possibilidade de 
emancipação dos educandos e dos educadores. Trata-se de um processo que se inicia com o movimento de transformação do docente em sua possibilidade e capacidade de autorreflexão crítica, como pressuposto capaz de fomentar a práxis refletida e revolucionária, que "[...] implica na ação e na reflexão dos homens sobre o mundo para transformá-lo" (FREIRE, 2001, p. 67).

Contudo, para que os educadores deem conta do sentido e significados de seu lugar de "ser e estar no mundo" e, por decorrência, de suas práticas docentes refletidas e fundamentadas no campo das teorias do conhecimento, faz-se necessária a superação do trabalho alienado e opressor pela concepção do trabalho enquanto princípio educativo. Dessa forma, na perspectiva dos pressupostos filosóficos, metodológicos e pedagógicos, interessa compreender a dialética da realidade em movimento para apreendêla e transformá-la. No cotidiano das vivências e experiências não existe neutralidade política e o papel dos docentes não está descolado do contexto social em que estes e os educandos são partes indissociáveis.

Ao assumir a educação enquanto um ato político, os educadores também assumem um determinado projeto de educação e, assim, o modelo de sociedade que se pretende afirmar, reproduzir ou contrapor. Portanto, sobre o alcance do projeto educacional em suas mais diversas possibilidades de concepção e de intervenção social, a postura e a atuação refletidas do docente são, sem dúvidas, reveladoras do sentido de sua forma de "ser e estar no mundo" e podem estar comprometidas com o propósito da redenção, da reprodução ou de transformação da sociedade (LUCKESI, 1994).

Destarte, em qualquer das situações apresentadas são estas, na prática, reveladoras do papel e da postura assumidas pelos educadores. Tais afirmações refutam o pragmatismo do paradigma positivista, também indutor da postura de pseudo-neutralidade do educador em suas práticas pedagógicas, em muitos casos, conformadas na "zona de conforto" e no "imobilismo" do pensamento único e de posturas e narrativas equivocadas.

Também na perspectiva da epistemologia da práxis, para melhor compreensão e apreensão, enquanto recurso de método, cabe afirmar a contribuição do pensamento marxista pautado nos 
princípios do materialismo histórico e dialético (MASSON, 2012), base teórico-epistemológica de relevante importância para movimentar e compreender os processos de construção do conhecimento. Ao educador cabe a possibilidade de assumir-se e, assim, dar conta de movimentar categorias analíticas e alcançar as totalizações nos dinâmicos e contraditórios movimentos da história.

São processos de construção do conhecimento protagonizados pelos educadores e educandos e que, partindo do real-concreto, do particular, permitem reconhecer as relações e imbricações com o geral (e vice-e-versa). Em se tratando de um movimento historicamente contextualizado, a tomada de consciência, tanto do educador-mediador quanto do educando, é capaz de potencializar intervenções solidárias, colaborativas e comprometidas com o propósito da transformação social: práxis.

Ainda sob inspiração do pensamento marxista, evocar a possibilidade da necessária postura ético-política do educador revolucionário no contraponto à postura de redenção e de reprodução do modelo de sociedade, definido à luz dos interesses de dominação e opressão das elites, é, com certeza, reafirmar a importante contribuição da educação escolar para o conjunto do processo de transformação social. Nesse sentido, Paulo Freire (2006) faz as seguintes considerações, a saber:

[...] Educadores e educandos não podemos, na verdade, escapar à rigorosidade ética. Mas, é preciso deixar claro que a ética de que falo não é a ética menor, restrita, do mercado, que se curva obediente aos interesses do lucro [...]. Falo, pelo contrário, da ética universal do ser humano. Da ética que condena o cinismo do discurso citado acima, que condena a exploração da força de trabalho do ser humano, que condena acusar por ouvir dizer, afirmar que alguém falou $A$ sabendo que foi dito $B$, falsear a verdade, iludir o incauto, golpear o fraco e indefeso, soterrar o sonho e a utopia, prometer sabendo que não cumprirá a promessa, testemunhar mentirosamente, falar mal dos outros pelo gosto de falar mal. A ética de que falo é a que se sabe traída e negada nos comportamentos 
grosseiramente imorais como na perversão hipócrita da pureza em puritanismo. A ética de que falo é a que se sabe afrontada na manifestação discriminatória de raça, de gênero, de classe. É por esta ética inseparável da prática educativa, não importa se trabalhamos com crianças, jovens ou com adultos, que devemos lutar. E a melhor maneira de por ela lutar é vivê-la em nossa prática, é testemunhá-la, vivaz, aos educandos, em nossas relações com eles [...] (FREIRE, 2006, p. 15).

Ao fim e a cabo, no âmago da sociedade capitalista, as relações de dominação e de opressão das classes dirigentes precisam ser consideradas e enfrentadas, quando se pretende discutir de forma fundamentada o modelo de sociedade vigente. É preciso enfatizar que, nessa mesma sociedade de classes, não há espaço para posturas de neutralidade e de heteronomia por parte dos educadores, sob pena destes se tornarem cúmplices do estado de barbárie que ameaça o estado de direito, as liberdades democráticas e o direito à vida com dignidade.

Nesse cenário de retrocessos e de tentativas evidentes de afirmação do neofascismo no Brasil, negar a ética enquanto virtude, proposta na Pedagogia da Autonomia de Paulo Freire, é referendar a onda inescrupulosa e perversa do mercado financeiro que, sob a égide do pensamento neoliberal, reduz as funções do Estado e transforma pessoas em objetos desprezíveis, descartáveis, alijados de seus direitos elementares.

O ato de educar como prática de liberdade evoca reconhecer o sentido da práxis refletida do docente mediante o compromisso com a proposta de transformação da sociedade a partir de si e, por conseguinte, do educando e do meio em que vivenciam e experienciam o cotidiano de suas existências materiais. É do particular para o geral, por sua vez alcançado, por meio do exercício da permanente contextualização e da sistematização, quando os processos políticos, econômicos, sociais e culturais se tornaram mais iluminados, compreendidos e apreendidos.

Cada vez mais se faz necessário o exercício da problematização para a ação refletida. A realidade do cotidiano de vida dos educadores e, principalmente, dos estudantes, em suas mais 
diversas possibilidades de posições sociais em curso, não está desvinculada dos fatos e fenômenos cada vez mais pautados pelo "obscurantismo", enquanto ameaça permanente das relações e da coesão social em sua totalidade. É nessa conjuntura que tenta ganhar força o movimento de imposição de novos valores sociais alimentados por sentimentos de misoginia, feminicídio, xenofobia, homofobia, preconceitos étnico-raciais, preconceito de classe, dentre outras manifestações degradantes. Situações que precisam ser enfrentadas no cotidiano, notadamente nas escolas.

Na perspectiva da epistemologia da práxis, e ancorados neste campo argumentativo, é que se torna importante buscar transpor a aparência dos fatos e fenômenos, em muitos casos naturalizados, para que, uma vez problematizados, permitam dar conta de novos sentidos e significados indispensáveis ao permanente movimento do pensamento reflexivo e crítico.

Nesse particular, por meio do exercício de diálogo entre os pressupostos teóricos e conceituais de Vygotsky e Freire, pretendeuse tornar menos cruel e intransitável o caminho para o necessário repensar sobre o comprometimento dos educadores, tendo em vista os permanentes desafios e ameaças ao projeto de educação libertadora e emancipatória dos sujeitos.

O fato de terem vivido em épocas e contextos diferentes não desqualifica e tampouco deslegitima o exercício de tentar estabelecer diálogos entre os estudos sócio-histórico-cultural de Vygotsky e a da Educação Libertadora de Paulo Freire. De acordo com Petroni e Souza (2009, p. 354), a primeira aproximação entre a Teoria Sócio-histórica de Vygotsky e a Pedagogia da Autonomia de Paulo Freire,

[...] está na base epistemológica. Ambos os autores se utilizam de conceitos do marxismo para fundamentarem seus postulados. Vygotsky cunha do marxismo o uso de instrumentos para a transformação da natureza, a partir do que ele elabora a noção de signo e sua função na transformação do psiquismo humano. Toma como base o materialismo dialético e histórico para compreender o contexto e as ações do sujeito, entendendo o fenômeno psicológico como em constante movimento [...]. 
Tanto para Vygotsky como para Freire, prevalece a concepção do homem como sujeito histórico-cultural. Com base no materialismo histórico e dialético, enquanto recurso de método, a reflexividade crítica sobre o movimento do real em suas contradições apresenta-se como possibilidade para transpor perspectivas e posturas pragmáticas e reducionistas, muitas delas em processo de naturalização, como já apontamos.

Uma vez mediado pela história, a partir do sujeito históricocultural compreendido em sua totalidade social, destacadas as condições materiais existentes, torna-se possível ressignificar os signos, os símbolos e a linguagem, enquanto estratégia capaz de promover o desenvolvimento da consciência crítica, a emancipação do oprimido e sua tomada de consciência para a transformação da realidade.

\section{PANDEMIA, PANDEMÔNIOS E ENSINO REMOTO: um pontual exercício de sistematização de experiências no Proeja.}

O contexto político atual já foi, parcialmente, elucidado. À luz das contribuições dos pensamentos vygotskiano e freireano relacionados ao movimento de potencialização do processo de produção do conhecimento científico e elaborado, interessa-nos, neste tópico, sistematizar as experiências (JIMENEZ, 2009) realizadas a partir da adoção do formato de ensino remoto junto às turmas dos Cursos Técnicos Integrados do Proeja do Ifes, em seus notórios impactos e contradições em relação à proposta de formação humana integral.

Com o agravamento do quadro de crise sanitária decorrente da pandemia do novo Coronavírus, foram suspensas as atividades letivas presenciais no Ifes, no início do ano letivo de 2020. A partir de então, face às diversas tentativas de adoção do formato de ensino remoto, inúmeras foram as manifestações de estudantes e professores do Proeja contrários a esse encaminhamento. A partir das orientações da pesquisa documental (CELLARD, 2008), depreendemos pelos documentos analisados que uma intensa mobilização foi feita por meio de reuniões virtuais, elaboração e 
publicação de notas de repúdio e de documentos fundamentados nas especificidades da modalidade EJA e nas condições objetivas da realidade de vida dos sujeitos jovens, adultos e idosos, o que resultaram na decisão de não adoção do ensino remoto no Proeja, nessa primeira imposição.

Contudo, no final do ano de 2020, sob a intensa pressão dos dirigentes, foi retomada a discussão sobre a implementação do ensino remoto no Proeja. Naquela ocasião, todos os documentos produzidos e suas linhas argumentativas pautadas na defesa dos estudantes em suas singularidades, notoriamente reconhecidas, deixaram de ser consideradas por parte dos educadores. A exemplo do Curso Técnico Integrado em Guia de Turismo e em Segurança do Trabalho que acabaram aderindo às atividades pedagógicas não presenciais - APNP. Tais atividades impuseram aos estudantes as opções do trancamento de matrícula ou a adesão, sob o risco de reprovação.

Contrariamente, nesse mesmo período, os Cursos Técnicos Integrados em Hospedagem e Metalurgia e de Qualificação em Cadista não aderiram às APNP e assumiram o compromisso de efetivarem as Atividades Complementares de Ensino - ACE. Essas ações educativas, não obrigatórias aos discentes, objetivam assegurar os vínculos institucionais e afetivos dos estudantes com a instituição e com professores, por meio da oferta de atividades temáticas, de cunho interdisciplinar e de caráter formativo, durante o período de suspensão das atividades letivas presenciais.

No início do ano de 2021, tais propostas - as APNP e ACE, foram implementadas nas turmas do Proeja. Porém, antes do término do semestre letivo definido pelo calendário escolar, a Coordenação de Ensino da Unidade Vitória promoveu uma avaliação parcial e um novo processo de decisão acerca dessas práticas educativas ${ }^{8}$. Contrariando a ordem sutilmente estabelecida, o Curso de Hospedagem e o de Qualificação em Cadista mantiveram a proposta de prosseguimento com os projetos em andamentos, que compunham as ACE.

8 As APNP foram mantidas nos cursos técnicos que já as tinham adotado e ampliadas para o Curso Técnico Integrado em Metalurgia. 
Concluída a primeira fase das experiências referentes à proposta de ensino remoto junto às turmas do Proeja, e contando com algumas iniciativas voltadas para o apoio financeiro para a inclusão digital de estudantes, o resultado, ainda que parcial, apontou sinais de comprometimento da oferta da EJA em Vitória, uma das três unidades de ensino do Ifes que ofertam essa modalidade.

De acordo com resultados parciais divulgados, no Curso Técnico Integrado em Guia de Turismo, grande parte dos estudantes desistiu, outros trancaram matrícula e, quanto aos demais discentes que aderiram às APNP, parte ficou retida em várias disciplinas. Como também apontam reduzida participação dos estudantes em atividades síncronas e assíncronas realizadas nas plataformas virtuais nos Cursos de Metalurgia e de Segurança do Trabalho (ATA DA REUNIÃO, 2021).

Para os docentes e educandos dos cursos que aderiram às APNP, a exaustão é uma realidade que, somada às dificuldades dos estudantes, inclusive daqueles com deficiências, em acompanhar as tarefas sem a presença e a mediação dos educadores, revela os impactos negativos do ensino remoto, por meio da adoção das APNP, nos cursos do Proeja.

Em especial, no Curso Técnico Integrado em Hospedagem, as propostas de $\mathrm{ACE}$, sob a orientação do coordenador e do trabalho de docentes comprometidos com esse curso, têm assegurado a participação, mesmo que flutuante, de aproximadamente $65 \%$ a $70 \%$ dos estudantes matriculados. Sob o lema "ninguém solta a mão de ninguém", os discentes passaram a ter dois encontros síncronos semanais, recebendo materiais impressos e digitais, pelo sistema acadêmico, e-mails e por meio do grupo de Whatsapp. Também passaram a ter acessos às informações oficiais, esclarecidos e motivados diariamente, inclusive durante o final de semana.

Cabe destacar que os encontros síncronos são pautados por metodologias participativas, a partir de discussões de temáticas relacionadas às ementas do curso, em diálogo permanente com a realidade dos estudantes, sem deixar de considerar as questões referentes à saúde pública, "desgoverno", desemprego, fome, pobreza, miséria e orientações de cuidados pessoais e dos familiares, 
extremamente necessários para a resistência e sobrevivências nesse cenário pandêmico que atravessamos.

Embora reconhecemos ser o ensino remoto, em suas atividades síncronas e assíncronas, um formato paliativo assumido na tentativa de manter o vínculo dos estudantes e reduzir a possibilidade de mais uma interrupção da trajetória escolar de estudantes jovens, adultos e idosos, o papel do educador, tanto em relação ao planejamento das atividades quanto (e principalmente) na permanente intermediação junto aos estudantes, tem se revelado uma importante estratégia pedagógica.

No caso específico das experiências relacionadas às ACE no Curso Técnico Integrado em Hospedagem, tanto a metodologia dos encontros síncronos, sempre pautada na interatividade entre educadores e educandos por meio da problematização de temáticas de alcance interdisciplinar, quanto as estratégias de estudos e de pesquisas orientadas enquanto atividades assíncronas permitem reconhecer novas possibilidades de repensar a prática docente.

Por meio da realização de entrevistas sobre os mais diversos temas junto a familiares e membros da comunidade, como também do registro e comentários sobre fatos, fenômenos e particularidades relacionados ao modo de vida dos estudantes em família e na comunidade, as práticas docentes se revelam inovadoras na medida em que valorizam a história de vida dos jovens, adultos e idosos e, no coletivo, abrem o debate sobre questões importantes para potencializar o processo de emancipação dos sujeitos: educandos e educadores.

Mesmo diante dos resultados negativos apresentados pelos cursos que adotaram as APNP, como explicar a insistência de grande parte dos educadores e gestores nesse formato de ensino que compromete a qualidade do processo de formação, assim como ameaça novamente interromper a trajetória escolar dos estudantes jovens, adultos e idosos? Com certeza, resposta para tal questão merece um maior aprofundamento no sentido de buscar melhor conhecimento das circunstâncias, dos fatos e dos fenômenos relacionados aos processos, em sua totalidade. Porém, não impedenos de apontar questões para o permanente exercício de reflexão 
crítica sobre as contradições do projeto de educação escolar pretendido pelas elites dominantes.

Nesse breve exercício de sistematização de experiências relacionadas aos Cursos Técnicos Integrados do Proeja, ressaltamos a importância da intencionalidade ética dos educadores, sem perder de vista as importantes contribuições de Vygotsky e de Paulo Freire quando chamam a atenção desses profissionais para o exercício permanente da práxis reflexiva, mediante as contradições do contexto político que cada vez mais exigem o compromisso político de resistência.

Para os estudantes que resistem, na sua expressiva maioria, a sala de aula é o lugar de produção do conhecimento junto à presença do educador. Cabe-nos permanecer problematizando a partir das incertezas que insistem em ameaçar a oferta da EJA, no Ifes. São permanentes os desafios frente às armadilhas que insistem em precarizar a escola no plano material e intelectual e, cada vez mais, desqualificar a importância do conhecimento científico elaborado e o papel do educador na escola pública brasileira.

\section{CONSIDERAÇÕES FINAIS}

O elemento central motivador dessa reflexão (não finalizada e que precisa ser ampliada) é justamente o acelerado processo de naturalização do movimento de precarização da educação escolar pública, no âmbito da pandemia do novo Coronavírus, e que faz coro com os interesses nefastos da "elite brasileira do atraso", em correspondência ao projeto de sucateamento das políticas sociais e apropriação do orçamento público para fins de acumulação privada.

Admitir cegamente, por imposição ou conveniências, receitas paliativas para aligeirar e comprometer a qualidade de ensino das escolas públicas, especialmente em relação a oferta da modalidade EJA, parecer ser, na nossa avaliação, uma estratégia para aniquilar de vez com o Proeja e com sua existência vinculada aos Institutos Federais.

Com certeza, a negação por meio da cegueira, intencional ou não, somada ao pensamento alienado e às práticas subservientes de gestores e docentes, são algumas das situações que denotam a 
opção em fugir do compromisso ético-político capaz de dar sentido à práxis reflexiva e contribuir com o processo de afirmação das políticas públicas de interesse popular, quiçá, dos processos mais complexos de intervenções e transformações sociais.

Mediante o arcabouço teórico e conceitual dos pensamentos vygotskiano e freireano, e tendo em vista o impasse que limita a presença em espaços de interrelações e interações sociais, a exemplo da sala de aula, como ressignificar o papel de mediador do educador, indispensável ao processo de produção do conhecimento científico elaborado, nesse particular, para os estudantes jovens, adultos e idosos, no contexto de permanentes desafios e ameaças? Nessa conjuntura de pandemia e de pandemônios, os problemas são cada vez mais complexos e as incertezas ainda maiores. Nesse ínterim, precisamos resistir na "rebeldia" e, assim, fazer valer a práxis reflexiva comprometida com o ato de revolucionar, sempre!

\section{REFERÊNCIAS}

ARAGÃO, Eugênio. Entrevista: diálogos em tempos de pandemia e pandemônios no Brasil. In: AUGUSTO, Cristiane B; SANTOS, Rogério D. dos.(Org.). Pandemias e pandemônios no Brasil. 1. ed. São Paulo: Tirant lo Blanch, 2020, p.13-14.

BRASIL. Programa Nacional de Integração da Educação Profissional com a Educação Básica na modalidade de Educação de Jovens e Adultos - PROEJA. Documento Base. Brasília: Setec, 2007.

Disponível em:

http://portal.mec.gov.br/setec/arquivos/pdf2/proeja_medio.pdf. Acesso em: 30 Jun. 2021.

CAMARGO, Sandra A. F.; ROSA, Sandra V. L. Internacionalização das políticas educacionais, trabalho docente e precarização do ensino. In: LIBÂNEO, José C.; FREITAS, Raquel A. M. M. (Orgs) Políticas educacionais neoliberais e escola pública: uma qualidade restrita de educação escolar. 1 ed. Goiânia: Editora Espaço Acadêmico, 2018. p. 227-298. Disponível em:

https://www.google.com/Politicas_Educacionais_Neoliberais_e_Escol 
a_Publica_-_uma_qualidade_restrita_de_educacao_escolar. Acesso em: 30 jun. 2021.

CELLARD, A. A análise documental. In: POUPART, J. et al. A pesquisa qualitativa: enfoques epistemológicos e metodológicos. Petrópolis: Vozes, 2008. p. 295-316.

CHAUÍ, M. Convite à Filosofia. 14. ed. São Paulo: Ática, 2010.

FREIRE, P. Educação como prática da liberdade. 23. ed. Rio de Janeiro: Paz e Terra, 1967.

FREIRE, P. Pedagogia da Autonomia. Saberes necessários à prática educativa. São Paulo: Paz e Terra, 2001.

FREIRE, P. Pedagogia do oprimido. 41. ed. Rio de Janeiro: Paz e Terra, 2006.

FREITAS, L. C. de. A reforma empresarial da educação: nova direita, velhas ideias. São Paulo: Expressão Popular, 2018.

GRAMSCl, A. Cadernos do cárcere. 2. ed. Rio de Janeiro: Civilização Brasileira, 2000. (v. 2).

JIMENEZ, M. R. M. La sistematización como proceso investigativo. O la búsqueda de la episteme de lãs prácticas. 2009. Disponível em: http://www.cepalforja.org/sistem/sistem_old/sistematizacion_como_ proceso_investigativo.pdf. Acesso em: 24 mar. 2021.

LUCKESI, C. C. Filosofia da Educação. São Paulo: Cortez Editora, 1994.

KUENZER, Acácia Z. Trabalho e escola: a flexibilização do ensino médio no contexto do regime de acumulação flexível. Educ. Soc., Campinas, v. 38, n. 139, p.331-354, abr./jun., 2017.

MARX, K. O capital: crítica da economia política, 10. ed., São Paulo: Difel, 1985.

MASSON, Gisele. As contribuições do método materialista histórico e dialético para a pesquisa sobre políticas educacionais. 2012. Trabalho apresentado ao $9^{\circ}$ SEMINÁRIO DE PESQUISA EM EDUCAÇÃO DA REGIÃO SUL - ANPED SUL. Caxias do Sul, 2012. 
MIRANDA, M. I. Conceitos centrais da teoria de Vygotsky e a prática pedagógica. Ensino em Re-Vista, v. 13, n. 1, p. 7-28, jul.2004/jul.2005.

PETRONI, Ana P.; SOUZA, Vera L. T. Vigotski e Paulo Freire: contribuições para a autonomia do professor. Revista Diálogo Educacional, Pontifícia Universidade Católica do Paraná, Paraná, v. 9, n. 27, p. 351-361, maio/ago. 2009.

VAZQUEZ, A. S. Filosofia da práxis. Rio de Janeiro: Paz e Terra, 1968.

VIGOTSKY, L.S. Pensamento e Linguagem. São Paulo, Martins Fontes, 1993.

VYGOTSKY. L.S. A formação social da mente. São Paulo: Livraria Martins Fontes Editora Ltda, 2002.

ZATTI, Vicente. A educação para a autonomia em Immanuel Kant e Paulo Freire. Dissertação (Mestrado em Educação) - Universidade Federal do Rio Grande do Sul, Porto Alegre, 2007.

Submetido em: Julho/ 2021.

Aceito em: Agosto/ 2021. 